\title{
Prevalence of asthma and exhaled nitric oxide are increased in bleachery workers exposed to ozone
}

\author{
A-C. Olin*, E. Andersson*, M. Andersson*, G. Granung*, S. Hagberg*, K. Torén*,\#
}

Prevalence of asthma and exhaled nitric oxide are increased in bleachery workers exposed to ozone. A-C. Olin, E. Andersson, M. Andersson, G. Granung, S. Hagberg, K. Torén. C) ERS Journals Ltd 2004.

ABSTRACT: The aims of the present study were to determine whether exposure to high peaks of ozone resulted in an increased prevalence of asthma or respiratory symptoms among bleachery workers and whether nitric oxide (NO) was elevated in the exhaled air of these workers.

Bleachery workers $(n=228)$ from three Swedish pulp mills who had been exposed to ozone, together with 63 unexposed control subjects, were investigated by means of spirometry, Phadiatop $\mathbb{R}$, exhaled and nasal NO and answers to a questionnaire concerning respiratory symptoms and exposure. Exposure to an ozone peak that gave rise to respiratory symptoms was defined as a "gassing".

Bleachery workers reporting four or more gassings involving ozone had an increased prevalence of adult-onset asthma, wheeze, and current asthma symptoms. They also had a higher median concentration of exhaled NO in comparison with those who reported no such gassings (19.2 versus 15.7 parts per billion). No such associations were found in respect of nasal NO.

The results from this study show that bleachery workers who have been repeatedly exposed to ozone gassings have an increased prevalence of adult-onset asthma. The results also indicate exhaled nitric oxide may be a marker of airway inflammation in bleachery workers who have been exposed to high peaks of ozone.

Eur Respir J 2004; 23: 87-92.
*Sections of Occupational and Environmental Medicine and ${ }^{\#}$ Allergology, Sahlgrenska University Hospital, Göteborg, Sweden.

Correspondence: A-C. Olin

Section of Occupational and Environmental Medicine

Sahlgrenska University Hospital

St Sigfridsgatan 85B

S-412 66 Göteborg

Sweden

Fax: 4631409728

E-mail: Anna-Carin.Olin@ymk.gu.se

Keywords: Airway inflammation

asthma

epidemiology

exhaled nitric oxide

occupational

ozone

Received: May 272002

Accepted after revision: September 72003
An early detection of respiratory health effects is of great importance, particularly for workers who are occupationally exposed to agents that increase the risk of asthma. It may lead to prompt action to improve the working environment or change the work or work tasks to reduce exposure, which has been shown to improve the prognosis or even prevent the development of occupational asthma [1].

Since it has been suggested that airway inflammation may be an early event in the development of asthma [2], the measurement of nitric oxide (NO) in exhaled air (eNO), could, as a possible early marker for airway inflammation, add valuable information to that from questionnaires and spirometry, when examining groups at increased risk. The authors have previously shown, in a study confined to a single pulpmill, that bleachery workers who have been exposed to high peaks of ozone and/or chlorine dioxide have increased exhaled NO and an increased prevalence of wheeze [3]. The authors have now repeated the study with a larger population of bleachery workers from three Swedish pulp mills using ozone as a bleaching agent, including the previously investigated workers.

Ozone was introduced as a new bleaching agent in the Swedish pulp industry in 1992. Process disturbances have since resulted in the accidental exposure of bleachery workers to high peak concentrations of ozone $(>1,000 \mathrm{ppb})$. Ozone is a respiratory irritant, and its respiratory health effects had already been described at the end of the 19th century. Symptoms following acute exposure peaks include irritation of the nose and throat, coughing, dyspnoea, chest pain and severe fatigue. It is well known that even short-term exposure to ozone at ambient concentrations ( $100-200 \mathrm{ppb})$ can result in airway inflammation [4], but it is still unclear whether such exposure will contribute to the development of newonset asthma. The inflammation after acute ozone exposure is mainly characterised by the influx and activation of neutrophils in the airways [5].

NO is involved in a wide range of physiological activities in the airways, one of the more important being vasodilatation, as well as a weak bronchodilating effect. Two enzymes, endothelial NO synthase and neuronal NO synthase, are responsible for this constitutive production of NO. Moreover, NO has an important role in host defence through its cytotoxicity against invading pathogens, including viruses, bacteria, and parasites, as well as tumour cells [6]. It has been shown that the NO production in the airways is enhanced by various inflammatory cytokines, such as tumour necrosis factor- $\alpha$, interleukin- $1 \beta$ and interferon- $\gamma$, stimulating an inducible NO synthase (iNOS). INOS is expressed in airway epithelial cells and macrophages, neutrophils and eosinophils, and produces $\mathrm{NO}$ at a high (nanomolar) rate.

NO in exhaled air is a marker of airway inflammation [7]. As the method is noninvasive and quick and easy for the subjects to perform, it well suited to use in epidemiological studies, adding important information. So far, the sensitivity or specificity for eNO to detect airway inflammation in a random population has not been examined. It seems to be elevated especially in subjects with atopic asthma or rhinitis [8], and to be positively associated with eosinophils in induced sputum [9]. There have been two studies of subjects with nonatopic asthma presenting normal levels of exhaled NO 
$[10,11]$. As in a previous study by the authors of bleachery workers exposed to ozone, elevated eNO has also been found to be associated with exposure to gas and dust in tunneldriving workers [12], as well as to potroom pollutants [13], all exposures that are predominantly characterised by neutrophilic inflammation.

The aims of the present study were to investigate whether exposure to peaks of ozone in bleachery workers involved an increased occurrence of respiratory symptoms or asthma and to determine whether NO was elevated in the exhaled air of these workers.

\section{Material and methods}

The study is part of a longitudinal study of workers from three Swedish sulphate pulp mills using ozone for bleaching. The subjects were examined twice, in 1995-1996 and 19981999 , on both occasions outside the pollen season. The results from investigations in 1995-1996 have previously been reported [14]. The present study, carried out in 1998-1999, concerned the workers from three pulp mills who were tested for exhaled and nasal NO and spirometry, besides providing blood samples and answering questionnaires.

All process workers, maintenance and laboratory workers $(n=261)$ in the bleaching departments of the three pulp mills were invited to take part in the study, as well as workers from two adjacent paper mills who were recruited as unexposed controls $(n=75)$. In the paper mills, which were producing printing paper, the controls were exposed to low levels of paper dust. The paper mill workers had a comparable demand on physical workload as the pulp mill workers and similar socio-economical backgrounds and educational levels. Of the 297 workers participating in the study, six exposed subjects had to be excluded on account of incomplete questionnaires. Altogether, 228 bleachery workers $(87 \%)$ and 63 control subjects $(84 \%)$ were included in the final analysis. Only the 15 exposed subjects who were unable to perform NO measurements were excluded. These subjects did not differ from the included subjects in respect of spirometry (vital capacity (VC), forced expiratory volume in one second (FEV1)) or respiratory symptoms. Basic data on the subjects are presented in table 1 . The study was approved by the Local Ethical Committee at Göteborg University and written informed consent was obtained from all the participants.

All subjects received a respiratory questionnaire by mail, with items similar to previous questionnaires [15]. Based on the answers, the subjects were defined as having (or not having) physician-diagnosed asthma, adult-onset asthma (i.e. physician-diagnosed asthma with an onset after aged 16 yrs), current asthma symptoms (episodes of wheeze or dyspnoea within the last 12 months) or wheeze. Rhinitis was defined as a positive answer to a question about nasal blockage, sneezing or runny nose lasting $>1$ month, without having a cold [16].

All subjects underwent spirometry with dry wedge spiro-

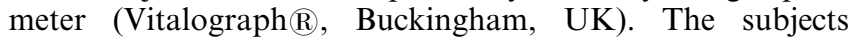
performed at least three technically acceptable trials, and the largest values for $\mathrm{VC}$ and FEV1 were registered and compared with predicted values [17]. Atopy was defined as a positive Phadiatop $\mathbb{R}$ (Pharmacia \& Upjohn Diagnostics, Uppsala, Sweden) [18]. Class 0 was regarded as negative and class 1 positive (atopic).

Exhaled NO was measured with the same equipment throughout the study period, including a chemiluminescence analyser (Ecophysics Breath Analyzer CLD 700 AL, Dürnten, Switzerland). A two-point calibration of the analyser was performed daily with a certified NO calibration gas. A special computer biofeedback system was used to enhance the regulation of exhalation flow rate (Exhalation Breath Analyzer ${ }^{\mathrm{TM}}$; Aerocrine AB, Stockholm, Sweden). The exhaled NO was measured during a slow single exhalation for $20 \mathrm{~s}$ against an oral pressure of $5 \mathrm{~cm} \mathrm{H}_{2} \mathrm{O}$ aiming at an exhalation flow rate of $50 \mathrm{~mL} \cdot \mathrm{s}^{-1}( \pm 10 \%)$, in accordance with American Thoracic Society recommendations [19]. The measurements were performed in triplicate at each occasion and the mean concentration ( $\mathrm{ppb}$ ) during the plateau phase was registered. Nasal NO was measured when the analyser was sampling nasal air from one nostril at a constant sample rate of $10 \mathrm{~mL} \cdot \mathrm{s}^{-1}$, with the subject holding their breath for $20 \mathrm{~s}$ and closing the velum voluntarily. A stable plateau of NO level on the on-line computer, during which the nasal NO concentration was registered, confirmed the closure of the velum. One measurement was performed in each nostril and the mean NO concentration ( $\mathrm{ppb}$ ) is presented.

The variability of the method has been examined on 25 healthy subjects on four different occasions 4 weeks apart. The intra-individual coefficient of variation was $9.2 \%$.

\section{Exposure}

The mills had been using chlorine/chlorine dioxide as bleaching agents since the 1950s, and periodically in 1992-1995. Chlorine dioxide was replaced by ozone as the bleaching agent in 1992-1993.

Under normal conditions, the concentration of ozone is low in a pulp mill. In the process of bleaching a concentration of $9 \%$ of ozone $(90,000,000 \mathrm{ppb})$ is used and during accidents, such as leakages from a pipe, short-term concentrations can, in the authors' estimation, be very high (>10,000 ppb). Stationary measurements of ozone concentrations in room air were carried out in the ozonator and mixing rooms, two critical areas for high exposure, in 1995-1996 at two of the mills, and have given an indication of the frequency of leakages. These measurements revealed ozone levels $>900 \mathrm{ppb}$ on

Table 1.-Basic data on bleachery workers who have been exposed to ozone and unexposed controls, with those exposed divided into different classes according to the number of reported exposure events (peaks) to ozone

\begin{tabular}{|c|c|c|c|c|c|}
\hline & \multirow[t]{2}{*}{ Unexposed } & \multicolumn{4}{|c|}{ Exposed } \\
\hline & & All & Low & Medium & High \\
\hline Subjects $n$ & 63 & 228 & 164 & 35 & 29 \\
\hline Age yrs mean \pm SD & $45.4 \pm 9.0$ & $44.7 \pm 8.7$ & $45.0 \pm 8.7$ & $42.2 \pm 8.9$ & $46.3 \pm 8.9$ \\
\hline Male/female $\mathrm{n}$ & $55 / 8$ & $215 / 13$ & $153 / 11$ & $34 / 1$ & $28 / 1$ \\
\hline Smokers n $(\%)$ & $7(11)$ & $32(14)$ & $25(15)$ & $6(17)$ & $1(3)$ \\
\hline Ex-smokers n $(\%)$ & $20(31)$ & $81(36)$ & $63(38)$ & $10(29)$ & $8(28)$ \\
\hline Never smokers n $(\%)$ & $36(57)$ & $115(50)$ & $76(46)$ & $19(54)$ & $20(69)$ \\
\hline Employment duration yrs mean \pm SD & $17.7 \pm 7.0$ & $20.2 \pm 11.3$ & $20.4 \pm 11.2$ & $16.2 \pm 10.9$ & $23.0 \pm 11.3$ \\
\hline
\end{tabular}


6 of the 360 days on which they took place [14]. However, the measured ozone levels point only to a very limited extent to the range of personal exposure when leakages have occurred. Hence the subjects' self-reported exposure must be used. As in previous studies the following questions were put to the subjects: "Have you ever been exposed to ozone resulting in coughing, wheezing, breathlessness or pain in the chest?" and if yes, "How many times?" An affirmative answer to the first question was defined as "ozone gassing". "Chlorine dioxide gassing" was defined in the same way.

The bleachery workers were divided into three classes of exposure according to the number of reported ozone gassings: 1) no reported gassings were defined as low exposure; 2) one to three gassings as medium exposure; and 3) four or more reported gassings as a high exposure. In addition, the bleachery workers were divided into four groups according to the number of years in which they reported ozone gassings $(0 \mathrm{yrs}$, 1-2 yrs, 3-4 yrs and $>4$ yrs). A similar analysis had been made in the authors' previous study [3]. These types of classification are mutually dependent, but the authors believe the latter can further help to identify subjects with a longer experience of repeated peak exposures.

\section{Analysis}

The statistical analyses of categorical data were based on the Chi-squared test, stratified for smoking. When there were few $(<5)$ subjects in a cell, Fisher's exact test was used, in which case the stratification for smoking was omitted. The continuous parameters were analysed with a nonparametric method (Kruskall-Wallis) and p-values are given. Trends were analysed with the Mantel-Haenszel test for trend and correlations were tested using Spearman's rank correlation coefficient. Since the NO data were not normally distributed, the medians are presented. The associations between the logtransformed values of exhaled $\mathrm{NO}$ and different explanatory variables (smoking, atopy, age, sex, ozone gassings, and chlorine-dioxide gassings and nasal NO) were tested using multiple linear regression models. The significance of the slope in the multivariate regression model was based on the $t$ distribution.

\section{Results}

The prevalence of respiratory symptoms, as well as of atopy, and their relation to exposure are presented in table 2. A comparison of all bleachery workers with control subjects showed a tendency towards more respiratory symptoms and asthma among the bleachery workers, but only reached statistical significance for wheeze $(p=0.047)$. There were statistically significant increasing trends among the bleachery workers for rhinitis, wheeze, adult-onset asthma and current asthma symptoms as exposure (the number of reported gassings) increased. There were also significantly higher prevalences of rhinitis, wheeze, adult-onset asthma and current-asthma symptoms in the group reporting the highest exposure, as compared with unexposed subjects. The prevalence of atopy was similar in all exposure and control groups.

There was no statistical difference in lung function between bleachery workers and controls although the workers in the highest exposure group had a tendency to lower FEV1 (99.9 versus $105.3 \%$ predicted, $\mathrm{p}=0.17$ ).

There was no significant difference in the median concentration of exhaled NO between bleachery workers and unexposed controls (15.9 ppb versus $16.9 \mathrm{ppb}, \mathrm{p}=0.32$ ). However, the workers in the highest exposure class, i.e. those reporting four or more ozone gassings, had a higher median eNO concentration in comparison with those reporting no such gassings (19.2 versus $15.7 \mathrm{ppb}, \mathrm{p}=0.04$ ). When subjects were considered according to atopic status, eNO was only found to be significantly higher among the nonatopic subjects with the highest exposure, 18.8 versus $14.9 \mathrm{ppb}$ ( $\mathrm{p}=0.034$, Kruskall Wallis test). There were only nine atopic subjects in the highest exposure class and they also had a higher eNO (25.8 versus $22.5 \mathrm{ppb}$ ) but this difference was not significant $(\mathrm{p}=0.78)$.

Among the exposed subjects there was an exposureresponse relationship for eNO to increase with an increasing number of years with ozone gassings ( $\mathrm{p}=0.02$, Kruskall-Wallis test for trend) (fig. 1). There was a similar trend with an increasing eNO with an increasing number of years with ozone gassings even when current smokers were excluded (medians 16.0, 19.3, 36.6 ppb, respectively, $\mathrm{p}=0.04$ ).

The median eNO concentration was greater in subjects with adult-onset asthma ( 24.7 versus $15.7 \mathrm{ppb}, \mathrm{p}=0.0021)$ than among those without asthma. The median eNO was $27.8 \mathrm{ppb}$ in subjects with adult-onset asthma who reported using inhaled glucocorticoids, as compared with $19.2 \mathrm{ppb}$ in those not using this medication $(\mathrm{p}=0.4)$.

Nasal NO was not associated with nasal symptoms or gassings. As the number of females included in the study was low the analysis was also performed excluding them, which did not change the results. In a linear multiple regression model (table 3), adjusting for to age, sex, atopy, adult-onset asthma, nasal NO, chlorine-dioxide gassings and smoking, there was a significant association between exhaled NO and the highest exposure to ozone.

Table 2. - Prevalence of respiratory symptoms, adult-onset asthma, and atopy among bleachery workers exposed to ozone and unexposed controls, the exposed workers divided into different classes according to the number of reported exposure events (peaks) to ozone. Low=no peaks, medium $=1-3$ peaks, high= 3 peaks. The analyses are stratified according to smoking habits

\begin{tabular}{|c|c|c|c|c|c|c|c|}
\hline & \multirow[t]{2}{*}{ Unexposed } & \multicolumn{4}{|c|}{ Exposed } & \multirow[t]{2}{*}{ p-value ${ }^{\#}$} & \multirow[t]{2}{*}{ p-value } \\
\hline & & All & Low & Medium & High & & \\
\hline Subjects $n$ & 63 & 228 & 164 & 35 & 29 & & \\
\hline Rhinitis & 21 & 25 & 22 & 24 & 46 & 0.03 & 0.03 \\
\hline Wheeze & 16 & 28 & 24 & 31 & 45 & 0.001 & 0.001 \\
\hline Adult-onset asthma & 3 & 8 & 5 & 11 & 18 & $0.02^{+, \S}$ & $0.005^{+}$ \\
\hline Current asthma symptoms & 10 & 16 & 12 & 23 & 35 & 0.003 & 0.007 \\
\hline Atopy & 27 & 27 & 26 & 29 & 31 & 0.69 & 0.64 \\
\hline
\end{tabular}

Data are presented as \% unless otherwise stated. ${ }^{\#}$ : unexposed versus high (Chi-squared test, stratified for smoking); ${ }^{\top}$ : trend among exposed (Mantel-Haenszel test for trend); ${ }^{+}$: not stratified for smoking; ${ }^{\S}$ : Fisher's exact test. 


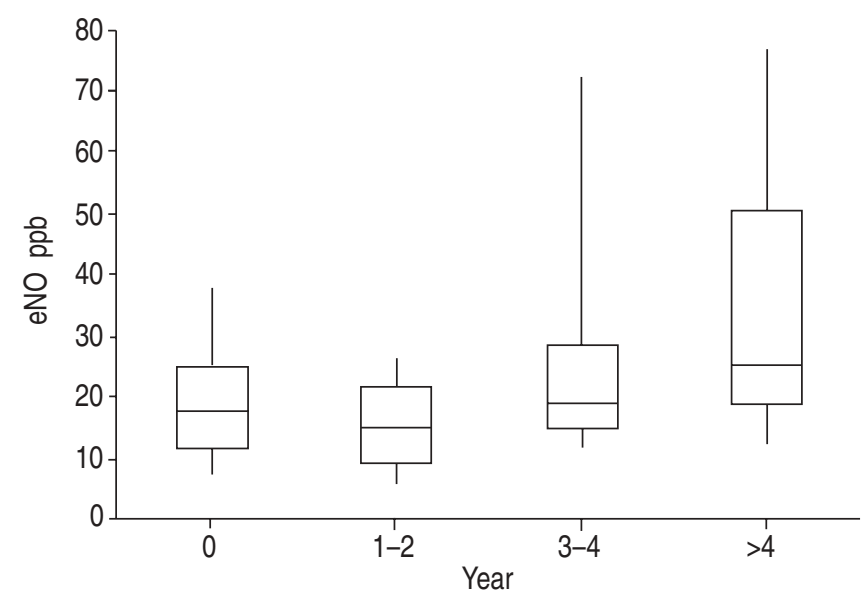

Fig. 1.-Exhaled nitric oxide (eNO) and association to numbers of years with ozone gassings. Box-plots show the medians and the 25 th and 75 th percentiles, and vertical bars the 10th and 90th percentile. $\mathrm{p}=0.02$ Kruskall Wallis test for trend. ppb: parts per billion.

\section{Discussion}

The main findings of the present study were that the subjects reporting the highest exposure to ozone had an increased prevalence of wheezing and adult-onset asthma, as well as higher levels of exhaled NO, in comparison with control subjects.

Many epidemiological studies have shown an increased prevalence of wheeze as well as decreased lung function among pulp-mill workers, and mainly among those that have been exposed to chlorine dioxide [20-22]. A history of gassing events, i.e. peak exposures, seems to be a major risk factor for that group [20]. It is also well known that single peak exposure to irritants can cause Reactive Airways Dysfunction Syndrome, and the term "irritant-induced asthma" has been introduced to describe asthma developing after repeated exposure to high levels of irritants [23]. To the authors' knowledge this is the first study indicating increased prevalence of adult-onset asthma after ozone gassings. Whether this is a casual relationship will be analysed in a prospective study of bleachery workers.

The study was subject to different biases. First, the exposure classification is based on the workers' own experience of respiratory symptoms in connection with exposure to ozone peaks. The self-reporting of gassings has also been used by

Table 3. - Variables included in a multiple linear regression model with exhaled nitric oxide as the dependent variable (log-transformed)

\begin{tabular}{lcc}
\hline Variable & Estimate & p-value \\
\hline Intercept & $2.05 \pm 0.26$ & \\
Sex & $0.14 \pm 0.15$ & 0.34 \\
Age yrs & $0.0041 \pm 0.0044$ & 0.35 \\
Smoking & $-0.66 \pm 0.11$ & $<0.0001$ \\
Atopy $^{+}$ & $0.22 \pm 0.087$ & 0.012 \\
Adult-onset asthma $^{\S}$ & $0.35 \pm 0.15$ & 0.022 \\
High ozone exposure $^{f}$ & $0.24 \pm 0.12$ & 0.050 \\
Chlorine dioxide gassings $^{\# \#}$ & $0.028 \pm 0.12$ & 0.81 \\
Nasal NO ppb & $0.00076 \pm 0.00022$ & 0.0006 \\
\hline
\end{tabular}

Data are presented as $\mathrm{n} \pm$ SEM unless otherwise stated. ${ }^{\#}: 1=$ male, $0=$ female; ๆ: $1=$ current smoking, $0=$ nonsmoking; ${ }^{+}$: positive Phadiatop $=1$, otherwise $=0 ;{ }^{\S}: 1=$ yes, $0=$ no; ${ }^{f}$ : experimental class high versus low, middle and controls; ${ }^{\# \#}$ : chlorine-dioxide gassing=1, no such gassing=0. NO: nitric oxide; ppb: parts per billion. others and has been considered the best estimate of exposure [20, 22]. Salisbury et al. [24] used a more strict method for identification of "gassed" subjects, i.e. the reports of the firstaid nurse at the mill, and gained a higher risk for negative respiratory health effects after gassings than KENNEDY et al. [20], who in the same study population used only selfreporting of gassings from questionnaire data. This indicates that self-reporting of gassings is less specific and may underestimate the true risks of gassings.

Self-reporting of gassings might also give rise to recall bias, as subjects with asthma may remember their exposure better or be more susceptible and therefore report exposure more frequently. BAKKE et al. [25] have shown that more specific outcome items, such as physician diagnosed-asthma, are less associated with bias of the reporting of exposure, as compared with less sensitive items, such as symptom-based questions. In the present study similar trends were found with increased reporting of exposure with increasing prevalence of both symptoms and physician-diagnosed asthma.

Comparing the subjects reporting asthma since childhood with the subjects with adult-onset asthma showed that from the seven subjects with childhood asthma only one reported gassings, as compared to nine of 19 subjects with adult-onset asthma. This indicates that increased susceptibility in subjects with asthma is unlikely to explain the results.

It is not known whether asthmatic subjects are more susceptible to developing respiratory symptoms after peak exposure to ozone than healthy subjects. Earlier studies have shown that hospital admissions of subjects with asthma increase when ambient ozone concentrations are elevated (>100 ppb) [26]. However, experimental studies, with ozone exposure limited to $2-400 \mathrm{ppb}$ for $2-4 \mathrm{~h}$, have shown that subjects with asthma and healthy subjects are equally susceptible to decrement of lung function and development of respiratory symptoms [26]. All subjects are however at risk to increased bronchial hyperrepsnsiveness after ozone exposure [27]. In asthmatic subjects this may imply that they are more prone to react to allergens or other irritants than healthy subjects.

These forms of bias may not only influence the prevalence of asthma and asthma symptoms in the highest exposure group, but also concerns eNO, since subjects with asthma have higher eNO. In an analysis of the data where all the subjects reporting physician-diagnosed asthma $(n=25)$ had been excluded, a similar exposure-response relationship was found, with levels of eNO increasing with reported exposures, though this did not attain statistical significance as the number of subjects were small. This indicates a true association between eNO and exposure to gassings.

The study has used answers to a questionnaire to classify asthma. It is well known that the question of physiciandiagnosed asthma is highly specific but less sensitive in identifying subjects with asthma [15]. The high specificity implies that those who are classified as having physiciandiagnosed asthma with a high certainty have asthma but several cases are overlooked. But even when a less specific definition of asthma that is more prone to misclassification was used, such as current asthma symptoms, similar results were found.

Smoking is known to decrease exhaled NO levels, and it is still uncertain whether eNO could be used for assessing airway inflammation within the smoker group. Since smokers were equally distributed among exposed and control subjects, although fewer in the highest exposed group, the authors chose to include them. The authors have also analysed the data with smokers excluded, and among the nonsmoking workers those reporting the highest exposure still had the highest eNO levels, but the significant exposure-response relationship disappeared. 
Factors such as diet [28] and viral infections are known to influence the measurement of exhaled NO. The subjects were therefore asked to refrain from nitrate-rich food for $4 \mathrm{~h}$ before the measurements. However, a few subjects who had forgotten this restriction had similar levels of eNO (16.6 versus $15.9 \mathrm{ppb}, \mathrm{p}=0.6$ ) and have consequently been included. In the case of subjects reporting that they had suffered from an upper respiratory tract infection (URTI) [16] in the 3 weeks prior to measuring, the examination was repeated on a later occasion, but when that was not possible the measurements were carried out anyway. Those subjects had slightly but not significantly higher eNO (18.1 versus $15.9 \mathrm{ppb}$, $\mathrm{p}=0.31$ ) than those without URTI. These were included, since excluding them did not change the results.

The results indicate that peak exposure to ozone can induce persistent airway inflammation, i.e. asthma and increased eNO, in susceptible workers. The elevated levels of eNO among the highest exposed workers are in agreement with the findings of a previous study by the authors with a smaller number of bleachery workers. However, the increase was modest, eNO being only $22 \%$ higher among workers reporting exposure to over more than three ozone peaks than among those who had not been exposed. As regards those reporting gassings over $>4$ yrs, the increase was $>100 \%$. It seems that lower exposures, with fewer than four gassings, will have limited effects on the respiratory system. This cannot be explained by the fact that the subjects reporting fewer gassings or fewer years with gassings had only been exposed when ozone bleaching had just started and had recovered. There was no association between recent histories of gassing (last year) and higher eNO.

Several studies have shown that the inflammatory process will be most pronounced in the distal airways after the exposure to ozone. A further examination of the workers that were identified as the most exposed in the 1996 study has accordingly shown them to have developed chronic bronchiolitis (Sandström, Umeå University, Sweden, personal communication). The method used to measure exhaled NO was not optimised to detect airway inflammation in the distal airways. Moreover, whereas increased exhaled NO seems, so far, to be mainly linked to eosinophilic inflammation, ozone, like other irritants, is suggested to induce a prominently neutrophilic inflammation. However, other groups exposed to irritants, including aluminium potroom workers [13] and tunnel-driving workers [12], have also been shown to have increased eNO. The nonsmoking potroom workers had a $60 \%$ higher level of eNO compared with nonsmoking controls [13], as also had tunnel-driving workers who had been exposed to gas and dust [12].

The results run contrary to those from experimental studies of acute ozone exposure in humans, including one from the authors' group, where no increase of exhaled NO was found after acute exposure at ozone in ambient levels [29, 30]. There might be several reasons for this apparent discrepancy. The nature of the exposure may differ. The workers have been exposed to repeated high peaks of ozone, whereas in experimental studies the subjects are exposed only once and then to a maximal ozone level of 2-400 ppb. Moreover, NO formed in the airways as a result of acute exposure might have been scavenged by other radicals and formed peroxynitrate [31], and hence would not be detected in exhaled air.

To conclude, the results from the current study show that bleachery workers who have been repeatedly exposed to ozone gassings have an increased prevalence of adult-onset asthma. The workers reporting the highest exposure also had elevated exhaled nitric oxide, which indicates that exhaled nitric oxide may be well used as marker of airway inflammation among such workers.
Acknowledgements. The study was supported by the Swedish Council for Worklife Research and the Swedish Association for Heart and Lung Diseases.

\section{References}

1. Toren K, Brisman J, Olin AC, Blanc PD. Asthma on the job: work-related factors in new-onset asthma and in exacerbations of pre-existing asthma. Respir Med 2000; 94: 529-535.

2. Laitinen LA, Laitinen A, Haahtela T. Airway mucosal inflammation even in patients with newly diagnosed asthma. Am Rev Respir Dis 1993; 147: 697-704.

3. Olin AC, Ljungkvist G, Bake B, Hagberg S, Henriksson L, Toren K. Exhaled nitric oxide among pulpmill workers reporting gassing incidents involving ozone and chlorine dioxide. Eur Respir J 1999; 14: 828-831.

4. Balmes JR. The role of ozone exposure in the epidemiology of asthma. Environ Health Perspect 1993; 101: Suppl. 4, 219224.

5. Koren HS, Devlin RB, Graham DE, et al. Ozone-induced inflammation in the lower airways of human subjects. $\mathrm{Am}$ Rev Respir Dis 1989; 139: 407-415.

6. Moncada S, Higgs EA. Endogenous nitric oxide: physiology, pathology and clinical relevance. Eur J Clin Invest 1991; 21: 361-374.

7. Kharitonov SA, Barnes PJ. Exhaled markers of pulmonary disease. Am J Respir Crit Care Med 2001; 163: 1693-1722.

8. Gratziou C, Lignos M, Dassiou M, Roussos C. Influence of atopy on exhaled nitric oxide in patients with stable asthma and rhinitis. Eur Respir J 1999; 14: 897-901.

9. Jatakanon A, Lim S, Kharitonov SA, Chung KF, Barnes PJ. Correlation between exhaled nitric oxide, sputum eosinophils, and methacholine responsiveness in patients with mild asthma. Thorax 1998; 53: 91-95.

10. Henriksen AH, Lingaas-Holmen T, Sue-Chu M, Bjermer L. Combined use of exhaled nitric oxide and airway hyperresponsiveness in characterizing asthma in a large population survey. Eur Respir J 2000; 15: 849-855.

11. Ludviksdottir D, Janson C, Hogman M, Hedenstrom H, Bjornsson E, Boman G. Exhaled nitric oxide and its relationship to airway responsiveness and atopy in asthma. BHR-Study Group. Respir Med 1999; 93: 552-556.

12. Ulvestad B, Lund MB, Bakke B, Djupesland PG, Kongerud $\mathrm{J}$, Boe $\mathbf{J}$. Gas and dust exposure in underground construction is associated with signs of airway inflammation. Eur Respir $J$ 2001; 17: 416-421.

13. Lund MB, Oksne PI, Hamre R, Kongerud J. Increased nitric oxide in exhaled air: an early marker of asthma in nonsmoking aluminium potroom workers? Occup Environ Med 2000; 57: 274-278.

14. Olin AC, Granung G, Hagberg S, et al. Respiratory health among bleachery workers exposed to ozone and chlorine dioxide. Scand J Work Environ Health 2002; 28: 117-123.

15. Toren K, Brisman J, Jarvholm B. Asthma and asthma-like symptoms in adults assessed by questionnaires. A literature review. Chest 1993; 104: 600-608.

16. Hellgren J, Toren K, Balder B, Palmqvist M, Lowhagen O, Karlsson G. Increased nasal mucosal swelling in subjects with asthma. Clin Exp Allergy 2002; 32: 64-69.

17. Berglund E, Birath $\mathrm{H}$, Bjure J, et al. Spirometric studies in normal subjects. Acta medica Scandinavica 1963; 173: 185191.

18. Matricardi PM, Nisini R, Pizzolo JG, d'Amelio R. The use of Phadiatop $\mathbb{R}$ in mass-screening programmes of inhalent allergies: advantages and limitations. Clin Exp Allergy: 20: 151-155.

19. American Thoracic Society. Recommendations for standardized procedures for the on-line and off-line measurement of exhaled lower respiratory nitric oxide and nasal nitric oxide 
in adults and children-1999. Am J Respir Crit Care Med 1999; 160: 2104-2117.

20. Kennedy SM, Enarson DA, Janssen RG, Chan-Yeung M. Lung health consequences of reported accidental chlorine gas exposures among pulpmill workers. Am Rev Respir Dis 1991; 143: 74-79.

21. Henneberger PK, Ferris BG Jr, Sheehe PR. Accidental gassing incidents and the pulmonary function of pulp mill workers. Am Rev Respir Dis 1993; 148: 63-67.

22. Henneberger PK, Lax MB, Ferris BG Jr. Decrements in spirometry values associated with chlorine gassing events and pulp mill work. Am J Respir Crit Care Med 1996; 153: 225-231.

23. Tarlo SM. Workplace respiratory irritants and asthma. Occup Med 2000; 15: 471-484.

24. Salisbury DA, Enarson DA, Chan-Yeung M, Kennedy SM. First-aid reports of acute chlorine gassing among pulpmill workers as predictors of lung health consequences. Am J Ind Med 1991; 20: 71-81.

25. Bakke PS, Hanoa R, Gulsvik A. Relation of occupational exposure to respiratory symptoms and asthma in a general population sample: self-reported versus interview-based exposure data. Am J Epidemiol 2001; 154: 477-483.
26. Committee of the Environmental and Occupational Health Assembly of the American Thoracic Society. Health effects of outdoor air pollution. Am J Respir Crit Care Med 1996; 153: 3-50.

27. Folinsbee LJ, McDonnell WF, Horstman DH. Pulmonary function and symptom responses after 6.6-hour exposure to $0.12 \mathrm{ppm}$ ozone with moderate exercise. JAPCA 1988; 38: $28-35$.

28. Olin AC, Aldenbratt A, Ekman A, et al. Increased nitric oxide in exhaled air after intake of a nitrate-rich meal. Respir Med 2001; 95: 153-158.

29. Olin AC, Stenfors N, Toren K, et al. Nitric oxide (NO) in exhaled air after experimental ozone exposure in humans. Respir Med 2001; 95: 491-495.

30. Nightingale JA, Rogers DF, Barnes PJ. Effect of inhaled ozone on exhaled nitric oxide, pulmonary function, and induced sputum in normal and asthmatic subjects. Thorax 1999; 54: 1061-1069.

31. Saleh D, Ernst P, Lim S, Barnes PJ, Giaid A. Increased formation of the potent oxidant peroxynitrite in the airways of asthmatic patients is associated with induction of nitric oxide synthase: effect of inhaled glucocorticoid. FASEB $J$ 1998; 12: 929-937. 